\title{
Impacts of passion with job, perceived justice on OCB and creative behaviors
}

\author{
Tran The Nam ${ }^{1}$, Nguyen Thi Thoa ${ }^{1}$ \\ ${ }^{1}$ University of Finance and Marketing, Vietnam \\ *Corresponding author: tranthenam@ufm.edu.vn
}

\begin{tabular}{|c|c|}
\hline ARTICLE INFO & ABSTRACT \\
\hline $\begin{array}{l}\text { DOI:10.46223/HCMCOUJS. } \\
\text { econ.en.11.1.988.2021 }\end{array}$ & $\begin{array}{l}\text { How to support employees to have more and more } \\
\text { organizational citizenship behaviors (OCB) and creative } \\
\text { behaviors is an interesting question not only for researchers but } \\
\text { also for practitioners. The aim of this study is to analyze the } \\
\text { impacts of passion with the job and perceived justice on OCB and }\end{array}$ \\
\hline Received: September $22^{\text {nd }}, 2020$ & \\
\hline Revised: January $2^{\text {nd }}, 2021$ & companies in Hochiminh city. Structural equation modeling was \\
\hline Accepted: January $8^{\text {th }}, 2021$ & $\begin{array}{l}\text { employed to test the proposed hypotheses by using the data of } 229 \\
\text { employees. Results of the study indicate that proposed } \\
\text { antecedents have significant influences on dependent constructs. } \\
\text { Such findings have implications for theory and practice. In theory, }\end{array}$ \\
\hline $\begin{array}{l}\text { Keywords: } \\
\text { passion with job, perceived } \\
\text { justice, organizational citizenship } \\
\text { behaviors, creative behaviors, } \\
\text { Smart PLS }\end{array}$ & $\begin{array}{l}\text { it supports the equity theory and the social exchange theory. In } \\
\text { practice, managers should carefully select the candidate who will } \\
\text { work for the organization and provide a comfortable working } \\
\text { environment in order to support employees to have voluntary } \\
\text { activities and creativity. }\end{array}$ \\
\hline
\end{tabular}

\section{Introduction}

According to Garg and Rastogi (2006), the success of an organization is significantly attributed to the engagement as well as the employees' effort. The amount of time and energy that employees spend on their work can largely affect the degree to which the companies can (DiPaola $\&$ da Neves, 2009). Introducing by Smith, Organ, and Near (1983), OCB is the concept that encompasses voluntary behaviors of employees and useful for organizations. It is of great importance to understand that OCB is supportive of the organization's success. There was countless research that analyzes the antecedents of OCB. Furthermore, in the era of technological revolution 4.0, innovation seems to take the lead in doing the company a favor when competing with rivals. The more innovative mindset that employees have when performing a job, the better the result will be. It is an interesting topic to find out how creative behaviors of employees can be influenced by antecedents (Akturan \& Çekmecelioğlu, 2016). Based on the equity theory and social exchange theory, the research analyzes the influences of the passion of job, perceived justice on OCB and creative behaviors of employees. Passion is defined as "a strong inclination or desire towards an activity that one likes and finds important and in which one invests time and energy" (Vallerand \& Houlfort, 2003). The research of Cheasakul and Varma (2016) concluded that OCB can be affected by passion with the job. Intrinsic motivation is essential for creative activities (Amabile, Hill, Hennessey, \& Tighe, 1994). It is likely that when people are passionate about their job, they will often come up with methods to get their work improved. Perceived justice is a vital element that affects employees' behaviors and work attitudes (Cohen-Charash \& Spector, 2001). 
The result of Chan and Lai research in 2017 was favorable to the idea that as employees are perceived as possessing more justice, they would have more OCB. Moreover, when people have voluntary and useful behaviors for the organization they work at a will, they can attempt new ideas, new ways to make their work better. OCB is positively affected by the creative behaviors of employees (Akturan \& Çekmecelioğlu, 2016).

\section{Theoretical basis}

\subsection{The conceptualization of key variables}

\subsubsection{Passion with job}

During the early twentieth-first century, the question "How people's lives can be worth living?" raised psychologists' concerns (Seligman \& Csikszentmihalyi, 2000). The new concept "Passion" was introduced by Vallerand et al. (2003): it is supposed to provide energy for people to pursue their work, cope up with challenges. A strong tendency toward an activity that is favorable to somebody and they are willing to spend time and energy has been defined as passion (Teng, 2019; Tran \& Nguyen, 2020; Vallerand et al., 2003). A passion is something that people reckon is part and parcel of their lives or something people like or something that the amount of time they spend is superior to others. Passion could result from an individual (e.g., one's idol), an activity (such as playing football, singing), or an object (e.g., stamp) (Vallerand, 2010; Vallerand \& Houlfort, 2003).

\subsubsection{Perceived justice}

Aguiar-Quintana, Araujo-Cabrera, and Park (2020); Colquitt, Greenberg, and ZapataPhelan (2005) argued that justice is an essential concept. It has considerable impacts on employees' attitudes as well as behaviors in an organization (Usmani \& Jamal, 2013). According to Greenberg (1990), "the degree to which the organizational decisions are considered to be fair by employees" reflects organizational justice or perceived justice by employees in organizations. Organizational justice is a multifaceted concept that covers three aspects. At first glance, McFarlin and Sweeney (1992) suggested two components: distributive justice and procedural justice (formal procedures). Distributive justice refers to how fair the outcomes that one person receives (Adams, 1965). Thibaut and Walker (1975) supposed that procedural justice is determined by the level of fairness of the process that results in the outcome. Later, the third component (interactional justice) was mentioned by Bies and Moag (1986). The subordinates' mindset about the fairness of the interpersonal treatment they received from leaders constitutes interactional justice. In this research, perceived justice is considered as the second-order constructs which include three first-order constructs: formal procedures, interactional justice, and distributive justice.

\subsubsection{Organizational citizenship behavior $(O C B)$}

The term "Organizational citizenship behavior" was first shown up in the article of Smith et al. in 1983, and lately, it drew numerous researchers' attention. There are wide varieties of definitions regarding OCB, however, the one introduced by Organ (1988) is considered to be the most renowned. Not only can the organization but members can also gain benefits from OCB. Those are individual and voluntary behaviors yet are not officially recognized by the organization. For instance, with the assistance of $\mathrm{OCB}$, the organization can be operated in a way that is more productive and efficient, and a higher level of customer satisfaction can also be achieved. Moreover, employees who possess OCB, have the lower ratio of intention to quit or absenteeism (N. P. Podsakoff, Whiting, Podsakoff, \& Blume, 2009). Seven types of OCB was mentioned in the research of Organ, Podsakoff, and MacKenzie (2006): altruism, generalized compliance, 
sportsmanship, civic virtue, courtesy, loyalty and self-development. However, other researchers saw eye to eye on the mindset that it is not a piece of cake to tell the seven kind of behaviors apart, therefore, they proposed only three followed behaviors: helping behavior, civic virtue, and sportsmanship (MacKenzie, Podsakoff, \& Fetter, 1991; Podsakoff \& MacKenzie, 1994; Podsakoff, MacKenzie, \& Fetter, 1993).

\subsubsection{Creative behaviors}

According to Amabile (1983) and Perry-Smith (2006), the manner in which innovative and useful ideas, products, services, processes, procedures, or solutions are produced is referred to as creativity. It came as no surprise that in the knowledge-based economy, the employees' creativity is crucial to an organization's existence and development (Newman, Tse, Schwarz \& Nielsen, 2018; Zhou \& Hoever, 2014). Furthermore, customer satisfaction and loyalty are also increased (Gumusluoglu \& Ilsev, 2009). Consequently, organizations need to come up with solutions to boost employees' creative behaviors (Gong, Huang, \& Farh, 2009) with a view to improving cutting-edge advantages. It is of great importance to keep in mind that innovation originates from the interaction between a person's thoughts and social-cultural environments, not a product of people's brains (Whitelock, Faulkner, \& Miell, 2008).

\subsection{Theoretical framework}

\subsubsection{Equity theory}

Equity theories were introduced by Adams (1965), (Pritchard, 1969). However, among these theories, the equity theory of Adams (1965) has gained widespread attention from researchers. Very often, what people pay (inputs) is compared to what they receive (outcomes) in one relationship. Outcomes and inputs form a ratio. People consciously or unconsciously compare his/her ratio with others. When a person perceives that his/her ratio bears a strong resemblance to others, equity occurs. In contrast, inequity shows up in response to the perception that his/ her ratio bear little or no resemblance to others. What is more, for those who are in direct relationship such as business partners or when both personal and other are related to a third party, for instance, two employees being paid by one manager, inequity can happen. In business settings, the business manager could take advantage of the implications withdrawn from the equity theory. It is advisable for authorities that employees should be surrounded with working environment where they perceive the fairness.

\subsubsection{Social exchange theory}

Since the year 1950s, social exchange theory was built as psychological theory and it served as well explanations for human's economic activities. At first sight, this theory was utilized to explain human behaviors (Homans, 1958), then organizational behaviors (Blau, 1964; Emerson, 1962). In the communication process, reciprocity is supposed to be the most important rule (Cropanzano \& Mitchell, 2005). People see eye to eye on this rule and others' behaviors are attributed to his/her behaviors (Cropanzano \& Mitchell, 2005). If one person provides a benefit, the receiver will think that he/she needs to offer a benefit as well. The benefit may be originated from social benefit (such as emotion, social impact) or economic benefit (money, goods, information) (Muthusamy \& White, 2005). According to this theory, if employees form the perception that what they contribute to the organization is recognized or the organization takes care of them, in all probability they will hold more positive feelings toward the organization, and they will be committed to the organization for such a long time. 


\subsection{Hypotheses}

According to Vallerand and Houlfort (2003), when people are passionate about the job, they want to do the job that they are favorable to, they can spend their time and energy on the job they are interested in and they want to contribute to the development of the organization. Though OCB are voluntary, user behaviors, the organization does not reward these officially (Organ, 1988). It might be that as employees are more passionate about the job, it stands high chances that they provide more OCB to the organization correspondingly. It is a matter of fact that when individuals are fond of a job or an organization, they can perform their job or work for the organization without hesitations or considering receiving any benefit in returns. The study of Cheasakul and Varma (2016) has confirmed the positive influence of passion on the job on OCB. Thus, the relationship between passion with job and OCB is hypothesized as follows:

\section{H1: Passion with job positively relates to $O C B$}

Once employees have creative behaviors, their daily tasks will be innovated efficiently (Amabile, 1983). When people perform the job with passion, they often think about how to get their work improved. In fact, it is not easy at all to invigorate the work without concentration. Therefore, if people have a passion for a job, they will end up having more innovative behaviors. The research of De Bernardi and Pedrini (2020) confirmed the idea that people are active, dynamic when they have a passion for something. Thus, the relationship between passion with the job and creative behaviors is hypothesized as follows:

\section{H2: Passion with job positively relates to creative behaviors}

In his research, Organ (1988) argued that OCB is affected by an important prefix: perceived justice. Moorman (1991) also pointed out the fact that the equity theory and the social exchange theory could serve as an explanation for the relationship between perceived justice and OCB. Employees will immerse the time and energy themselves to resolve the problems if inequity arises (Adams, 1965). Therefore, having more voluntary and useful actions for the organization is not easy for them. According to the literature, as individuals sense the treatment is fairer, they have more tendency to participate in OCB (e.g., Wong, Ngo, \& Wong, 2006). Obviously, only when employees perceive that their contributions are evaluated fairly by their leaders can they advocate the organization by providing more OCBs. If inequity appears to someone, he/she will do only what is compulsory (by the organization) and stops his/her OCB (Fassina, Jones, \& Uggerslev, 2007). Numerous research has confirmed the positive impacts of perceived justice on OCB. Cohen-Charash and Spector (2001) argued that distributive justice and procedural justice (two dimensions of perceived justice) were significant antecedents of OCB while the study of Colquitt, Colon, Wesson, Porter, and Ng (2001) concluded that OCB was supportive of fair interpersonal treatment from managers. Therefore, the relationship between perceived justice and OCB is hypothesized as follows:

\section{H3: Perceived justice positively relates to $O C B$}

The organization can take advantage of employees' creative behaviors by having higher productivity, better work quality, or customer satisfaction and loyalty (Gumusluoglu \& Ilsev, 2009; Zhou \& Hoever, 2014). OCB is nothing sort of user behavior for not only organizations but also for individuals. (Podsakoff et al., 2009). Correspondingly, when employees have more OCB, there is high certainty that they have more creative behaviors. It is argued that potential creativity can be increased when employees want to contribute voluntarily to the success of the organization. The research of Akturan and Çekmecelioğlu (2016) also confirmed the effects of OCB on creative behaviors. Thus, the relationship between OCB and creative behaviors is hypothesized as follows: 
H4: OCB positively relates to creative behaviors

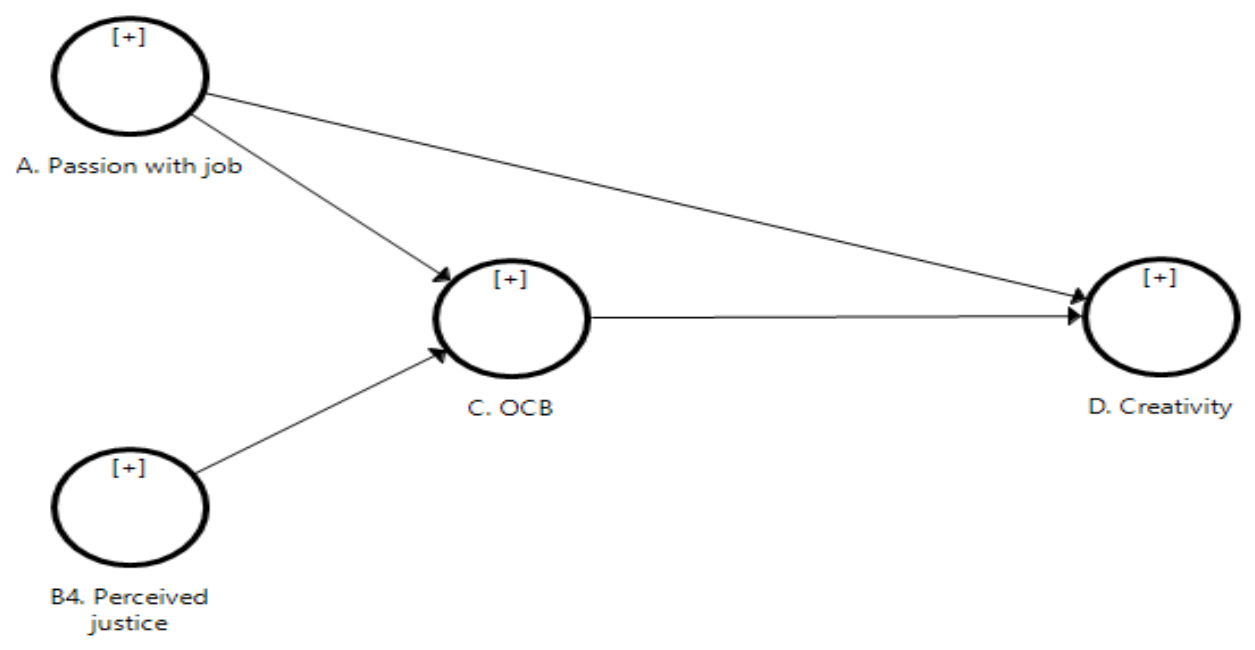

Figure 1. The proposed research model

\section{Research methods}

With a view to evaluating the proposed relationships between variables, a quantitative approach was utilized by using cross-sectional data. Items of Formal procedures, Interactive justice and Distributive justice were adopted from Moorman (1991). Passion with job three items was adopted from Carbonneau, Vallerand, Fernet, and Guay (2008), OCB five items were adopted from Özdemir and Ergun (2015). Finally, the research of Rice (2006) provided six items for Creative behaviors. Furthermore, a global single-item "Please assess the extent to which you perceived the justice in your organization" was created to measure the construct "Perceived justice". The five-point Likert-type scale ranging 1 (strongly disagree) to 5 (strongly agree) was used to measure items. Consequently, the authors built a survey questionnaire to gather primary data from employees in different industries in Hochiminh city, the most important economic center in Vietnam.

The survey is comprised of two stages. Firstly, a pilot with 57 reviewees was done to check the reliability and validity of indicators. The authors also contacted respondents to check the meaning of questionnaires and to revise the questionnaires (if necessary). The result of the pilot confirmed that the questionnaires are appropriate for the official survey. Next, the authors conducted the official survey. A total of 229 questionnaires were received for data analysis.

The convenient sampling method was utilized to conduct the survey. The authors decided to use an online survey. The link to the survey was sent to friends from all walks of life. With the software Smart PLS, the number of over 200 respondents is satisfied to analyze (Hair, Hult, Ringle, \& Sarstedt, 2017).

Partial least squares structural equation modeling (PLS-SEM) was used by using Smart PLS version 3.2.8. PLS-SEM is advantageous over co-variance-based SEM, particularly once there is a complex model to evaluate and the research framework is exploratory in nature (Hair et al., 2017). The conceptual framework of this study was complex as shown in Figure 1. Hence, PLS-SEM was preferred for data analysis in this study. PLS-SEM separately evaluates measurement and structural model.

\section{Research results}

Most of the respondents were less than 35-year-old (92\%), were having a bachelor's degree 
and above (96\%). Half of the respondents are white-collar workers. More than half (57\%) of reviewers' income ranged from 300 USD to 700 USD/month and $20 \%$ of respondents were having a monthly income of $700 \mathrm{USD} / \mathrm{month}$ and above.

Perceived justice is a second-order construct. Therefore, the relationship between the second-order construct (Perceived justice) and its first-order constructs (Formal procedures, Interactive justice, Distributive justice) must be analyzed before assessing the influences of exogenous constructs on endogenous latent variables.

\subsection{Assessment of the relationship between the second-order construct and its first- order constructs}

It is vital to understand that "Perceived justice" is a reflective-formative higher-order construct. Therefore, there are two steps in order to evaluate the relationship between the secondorder construct and its first-order constructs:

$\checkmark$ Step 1: Assess the indicator reliability, the internal consistency, the convergent validity and discriminant validity of three first-order constructs (Formal procedures, Interactive justice, and Distributive justice).

$\checkmark$ Step 2: Assess the convergent validity, the collinearity issues, the significance and relevance of the formative indicators of the second-order construct (Perceived justice) .

4.1.1. Assess the indicator reliability, the internal consistency, the convergent validity and discriminant validity of three first-order constructs (Formal procedures, Interactive justice, and Distributive justice)

\section{Table 1}

Variables' information

\begin{tabular}{|c|c|c|c|c|}
\hline Variables & Outer loading & $\mathbf{C R}$ & AVE & $\begin{array}{l}\text { Outer } \\
\text { weight }\end{array}$ \\
\hline A. Passion with job & & 0.914 & 0.780 & \\
\hline A1 & 0.911 & & & 0.404 \\
\hline A2 & 0.849 & & & 0.367 \\
\hline A3 & 0.888 & & & 0.360 \\
\hline B1. Formal procedures & & 0.944 & 0.737 & \\
\hline B11 & 0.825 & & & 0.180 \\
\hline B12 & 0.891 & & & 0.202 \\
\hline B13 & 0.843 & & & 0.190 \\
\hline B14 & 0.849 & & & 0.191 \\
\hline B15 & 0.863 & & & 0.200 \\
\hline $\mathrm{B} 16$ & 0.878 & & & 0.201 \\
\hline B2. Interactive justice & & 0.937 & 0.715 & \\
\hline $\mathrm{B} 21$ & 0.815 & & & 0.195 \\
\hline $\mathrm{B} 22$ & 0.754 & & & 0.164 \\
\hline $\mathrm{B} 23$ & 0.804 & & & 0.200 \\
\hline
\end{tabular}




\begin{tabular}{|c|c|c|c|c|}
\hline Variables & Outer loading & $\mathbf{C R}$ & AVE & $\begin{array}{l}\text { Outer } \\
\text { weight }\end{array}$ \\
\hline B24 & 0.906 & & & 0.210 \\
\hline $\mathrm{B} 25$ & 0.910 & & & 0.215 \\
\hline B26 & 0.872 & & & 0.196 \\
\hline B3. Distributive justice & & 0.930 & 0.728 & \\
\hline B31 & 0.867 & & & 0.248 \\
\hline B32 & 0.730 & & & 0.199 \\
\hline B33 & 0.921 & & & 0.250 \\
\hline B34 & 0.913 & & & 0.255 \\
\hline B35 & 0.822 & & & 0.214 \\
\hline \multicolumn{5}{|l|}{ B4. Perceived justice } \\
\hline B1 & 0.865 & & & 0.397 \\
\hline $\mathrm{B} 2$ & 0.884 & & & 0.411 \\
\hline B3 & 0.866 & & & 0.339 \\
\hline C. Organizational citizenship behaviors & & 0.897 & 0.635 & \\
\hline $\mathrm{C} 1$ & 0.802 & & & 0.275 \\
\hline $\mathrm{C} 2$ & 0.801 & & & 0.256 \\
\hline $\mathrm{C} 3$ & 0.797 & & & 0.251 \\
\hline $\mathrm{C} 4$ & 0.775 & & & 0.232 \\
\hline $\mathrm{C} 5$ & 0.808 & & & 0.241 \\
\hline D. Creative behaviors & & 0.928 & 0.682 & \\
\hline D1 & 0.770 & & & 0.193 \\
\hline D2 & 0.883 & & & 0.215 \\
\hline D3 & 0.862 & & & 0.203 \\
\hline D4 & 0.761 & & & 0.175 \\
\hline D5 & 0.867 & & & 0.213 \\
\hline D6 & 0.804 & & & 0.210 \\
\hline
\end{tabular}

Source: Smartpls 3.0 processing results of authors

Indicators with low outer loading below 0.4 should be removed from the constructs while others higher than 0.7 should be kept from the constructs (Bagozzi, Yi, \& Phillips, 1991; Hair, Ringle, \& Sarstedt, 2011). Besides that, indicators with outer loadings between 0.4 and 0.7 should be dropped only when dropping them leads to the improvement in the composite reliability or the average variance extracted. Based on this rule, all indicators of the three first orders are kept. With a CR value higher than 0.7, all constructs achieve internal consistency (Hair et al., 2017). Thanks to an AVE value higher than 0.5 , it is possible to conclude that all three first-order variables have convergent validity (Hair et al., 2017). 


\section{Table 2}

HTMT ratio

\begin{tabular}{|l|r|r|r|r|}
\hline & $\begin{array}{c}\text { B1. Formal } \\
\text { procedures }\end{array}$ & $\begin{array}{c}\text { B2. Interactive } \\
\text { justice }\end{array}$ & $\begin{array}{c}\text { A. Passion with } \\
\text { job }\end{array}$ & C. OCB \\
\hline B2. Interactive justice & 0.665 & & & \\
\hline B3. Distributive justice & 0.685 & 0.733 & & \\
\hline C. OCB & & & 0.638 & \\
\hline D. Creative behaviors & & & 0.750 & 0.802 \\
\hline
\end{tabular}

Source: Smartpls 3.0 processing results of authors

HTMT ratio was used to assess the discriminant validity. Thanks to an HTMT ratio below 0.900, all variables achieve discriminant validity (Henseler, Ringle, \& Sarstedt, 2014).

4.1.2. Assess the convergent validity, the collinearity issues, the significance and relevance of the formative indicators of the second-order construct (Perceived justice)

The redundancy analysis of Perceived justice yields an estimate of 0.928 , which is above the recommended threshold of 0.70 , thus providing support for the formative construct's convergent validity (Hair et al., 2017).

\section{Table 3}

VIF values

\begin{tabular}{|l|c|c|c|}
\hline & B4. Perceived justice & C. OCB & D. Creative behaviors \\
\hline B1. Formal procedures & 1.881 & & \\
\hline B2. Interactive justice & 2.056 & & \\
\hline B3. Distributive justice & 2.116 & & \\
\hline B4. Perceived justice & & 1.697 & \\
\hline A. Passion with job & & 1.697 & 1.436 \\
\hline C. OCB & & & 1.436 \\
\hline
\end{tabular}

Source: Smartpls 3.0 processing results of authors

Three first-order constructs have VIF values of 1.881, 2.056 and 2.116, respectively. Hence, VIF values are uniformly below the threshold value of 5. Therefore, collinearity does not reach critical levels in the formative constructs.

\section{Table 4}

The relationship between first-order construct and second-order constructs

\begin{tabular}{|l|c|c|c|}
\hline \multicolumn{1}{|c|}{ Relationship } & Coefficient & P Values & Conclusion \\
\hline B1. Formal procedures -> B4. Perceived justice & 0.389 & $0 \%$ & Supported \\
\hline B2. Interactive justice -> B4. Perceived justice & 0.422 & $0 \%$ & Supported \\
\hline B3. Distributive justice -> B4. Perceived justice & 0.335 & $0 \%$ & Supported \\
\hline
\end{tabular}

Source: Smartpls 3.0 processing results of authors 
All $\mathrm{p}$ values are less than 5\%, therefore, all three indicators (Formal procedures, Interactive justice, and Distributive justice) have significance and relevance.

\subsection{Assessment of the measurement model}

The information provided in Table 2 and Table 3 demonstrated that all constructs (Passion with the job, OCB and Creative behaviors) achieve the convergent and discriminant validity while indicators have reliability and consistency.

\subsection{Assessment of the structural model}

It is necessary to evaluate six issues: collinearity issues, the significance and relevance of the structural model relationships, the level of R2, the $\mathrm{f} 2$ effect size, the predictive relevance Q2 and the effect size $\mathrm{q} 2$.

From the information in Table 4, with all inner VIF values which are less than 5 , it is conclusive that collinearity issues do not exist in this model (Hair et al., 2017).

Table 5

The path coefficient and p-value

\begin{tabular}{|c|l|c|c|c|}
\hline Hypothesis & \multicolumn{1}{|c|}{ Content } & Coefficient & P Values & Conclusion \\
\hline H1 & A. Passion with job -> C. OCB & 0.196 & $0 \%$ & Supported \\
\hline H2 & A. Passion with job -> D. Creative behaviors & 0.389 & $0 \%$ & Supported \\
\hline H3 & B4. Perceived justice -> C. OCB & 0.554 & $0 \%$ & Supported \\
\hline H4 & C. OCB -> D. Creative behaviors & 0.497 & $0 \%$ & Supported \\
\hline
\end{tabular}

Source: Smartpls 3.0 processing results of authors

Most researchers use $\mathrm{p}$ values to assess significance levels. When assuming a significance level of $5 \%$, the p-value must be smaller than 0.05 to conclude that the relationship under consideration is significant at a 5\% level. The results in Table 6 show that Passion for the job was having a positive and significant impact on OCB and on Creative behaviors. Therefore, $\mathrm{H} 1$ and H2 were supported. Similarly, Perceived justice was found to have a positive and significant influence on OCB. Hence, H3 was also supported. Finally, OCB was having a positive and significant impact on Creative behaviors. Both two exogenous constructs "Passion with the job" and "Perceived justice" have positive impacts on the endogenous latent variable "OCB" but "Perceived justice" has greater impacts than "Passion with job" when the coefficient value is greater (0.554 in compared with 0.196).

\section{Table 6}

R-square and Q-square values

\begin{tabular}{|l|c|c|c|c|}
\hline \multicolumn{1}{|c|}{ Variables } & $\mathbf{R}^{\mathbf{2}}$ & Level of predictive accuracy & $\mathbf{Q}^{\mathbf{2}}$ & Predictive relevance \\
\hline C. OCB & 0.484 & Moderate & 0.276 & Significant \\
\hline D. Creative behaviors & 0.612 & Moderate & 0.384 & Significant \\
\hline
\end{tabular}

Source: Smartpls 3.0 processing results of authors

The $\mathrm{R}^{2}$ value ranges from 0 to 1 , with higher levels indicating higher levels of predictive accuracy. $\mathrm{R}^{2}$ values of $0.75,0.50$, or 0.25 for endogenous latent variables can, as a rule of thumb, be respectively described as substantial, moderate, or weak (Hair et al., 2011; Henseler, Ringle, \& 
Sinkovics, 2009). However, it is essential to understand that it is not easy to provide rules of thumb for acceptable $\mathrm{R}^{2}$ values as this depends on the model complexity and the research discipline. As can be seen in the Table 7 , the $\mathrm{R}^{2}$ value is quite high. Only two exogenous constructs ("Passion with job" and "Perceived justice") can explain nearly $50 \%(48,4 \%)$ of the movement of the endogenous latent variable "OCB". Similarly, $61.2 \%$ of the movement of the endogenous construct "Creative behaviors" is explained by only two exogenous construct "Passion with job" and "OCB". It is conclusive that the proposed research model reaches the parsimony when there are only two exogenous constructs that can explain a half of the movement of the endogenous constructs.

$Q^{2}$ value is another criteria to assess predictive accuracy introduced by Geisser (1974) and Stone (1974). This measure is an indicator of the model's out-of-sample predictive power or predictive relevance. $Q^{2}$ values larger than zero for a specific reflective endogenous latent variable indicate the path model's predictive relevance for a particular dependent construct. The result of the Smart PLS analysis showed that exogenous constructs have the predictive relevance with endogenous latent variables.

\section{Table 7}

The effect size f-square and q-square

\begin{tabular}{|c|l|c|c|c|c|}
\hline Hypothesis & \multicolumn{1}{|c|}{ Content } & \multicolumn{1}{|c|}{$\mathbf{f 2}$} & $\begin{array}{c}\text { Level of } \\
\text { effects }\end{array}$ & q2 & $\begin{array}{c}\text { Predictive } \\
\text { relevance }\end{array}$ \\
\hline H1 & A. Passion with job -> C. OCB & 0.044 & Small & 0.015 & Small \\
\hline H2 & $\begin{array}{l}\text { A. Passion with job -> D. Creative } \\
\text { behaviors }\end{array}$ & 0.272 & Medium & 0.112 & Small \\
\hline H3 & B4. Perceived justice -> C. OCB & 0.351 & Large & 0.146 & Medium \\
\hline H4 & C. OCB -> D. Creative behaviors & 0.443 & Large & 0.057 & Small \\
\hline
\end{tabular}

Source: Smartpls 3.0 processing results of authors

In addition to evaluating the $\mathrm{R} 2$ values of all endogenous constructs, the change in the R2 value when a specified exogenous construct is omitted from the model can be used to evaluate whether the omitted construct has a substantive impact on the endogenous constructs. This measure is referred to as the $\mathrm{f} 2$ effect size and is increasingly encouraged by journal editors and reviewers. Guidelines for assessing $f 2$ are that values of $0.02,0.15$ and 0.35 , respectively, represent small, medium, and large effects (Cohen, 1988) of the exogenous latent variable. Effect size values of less than 0.02 indicate that there is no effect. From the information in Table 8 , it is conclusive that Perceived justice is an important antecedent of OCB and OCB is a vital antecedent of Creative behaviors.

Similar to the f2 effect size approach for assessing R2 values, the relative impact of predictive relevance can be compared by means of the measure to the $\mathrm{q} 2$ effect size. As a relative measure of predictive relevance, values of $0.02,0.15$, and 0.35 indicate that an exogenous construct has a small, medium, or large predictive relevance, respectively, for a certain endogenous construct. Only Perceived justice has a medium level of predictive relevance on OCB while in another hypothesis, exogenous variables have small predictive relevance on endogenous constructs.

In conclusion, the result of the survey proved the importance of the independent variable "Perceived justice" and "Passion with the job" with the dependent variable "OCB" and the essence of the exogenous construct "OCB" with the endogenous "Creative behaviors". The proposed 
research model is quite useful when it has only a few exogenous constructs, but it explains well the movement of endogenous latent variables.

\section{Conclusions}

\subsection{Theoretical implications}

This research is conducted to test how Passion with the job and Perceived justice affects OCB and how creative behaviors are influenced by Passion with job and OCB. The results revealed that Passion for the job and Perceived justice have positive and significant impacts on OCB. The results are in accordance with the work of Cheasakul and Varma (2016) and of Cohen-Charash and Spector (2001). On the other hand, the research also confirmed the impacts of Passion with the job and of OCB on Creativity. The results are in with the study of De Bernardi and Pedrini (2020) and of Akturan and Çekmecelioğlu (2016). By conducting the research, the equity theory and the social exchange theory is supported and strengthened. Moreover, another contribution of the research is applying a second-order construct with the concept "Perceived justice". In fact, there are numerous studies about perceived justice but not many studies treat this construct as a reflective-formative higher-order construct.

\subsection{Practical implications}

The results show that both Passions with the job and Perceived justice have positive and significant influences on OCB. However, perceived justice outweighs passion with the job in terms of the degree of the impact they have (see Table 6). Therefore, to talk employees into having more organizational citizenship behaviors, a working environment that promotes better justice must be provided by the managers. Based on the value of outer weight (see Table 2), among three components of Perceived justice, workers highly appreciate interactive justice. Thus, it is conclusive that the care and the evaluation of supervisors are very important to the subordinate. Obviously, employees do not take leaders' caring for granted. Being a part of the organization, employees place high hope on managers that their contributions will be recognized reasonably. What is more, the manager's evaluation is also crucial to their career.

Passion for the job also has significant impacts on OCB and creative behaviors. Firstly, candidates must be selected carefully regardless of any position in the. It is down to earth that when people enjoy their job, they would be all ears to perform their job and contribute more to the organization. Secondly, for employees who are working in the company, authorities should put reasonable challenges for employees. If they are passionate about their job, challenges are their motivations rather than obstacles. It will force them to the fullest and boost their creativity. Furthermore, in some cases, employees feel that there is a discrepancy or inconsistency between the qualification that they have and the characteristic of the work that they undergo. Leaders should apply the internal transfer policy to help employees to get back the passion for the job.

\subsection{Limitations and further research}

Although the results of this study add to the current knowledge, nonetheless, certain limitations are also acknowledged that highlight the avenue for future research. Firstly, not only two factors: the passion for the job and perceived justice influences OCB and creative behaviors. Others are not included in this research which brings about chances for further research. Secondly, the study did not analyze the influence of demographic elements on OCB and creative behaviors. Future research may consider the longitudinal approach to further authenticate the results of this study while this research was cross-sectional in nature. Finally, in order to gather better findings, this study should be done in a wide range of regions and cultures. 


\section{References}

Adams, J. S. (1965). Inequity in social exchange. Advances in Experimental Social Psychology, 2, 267-299. doi:10.1016/S0065-2601(08)60108-2

Aguiar-Quintana, T., Araujo-Cabrera, Y., \& Park, S. (2020). The sequential relationships of hotel employees' perceived justice, commitment, and organizational citizenship behaviour in a high unemployment context. Tourism Management Perspectives, 35, Article 100676. doi:10.1016/j.tmp.2020.100676

Akturan, A., \& Çekmecelioğlu, H. G. (2016). The effects of knowledge sharing and organizational citizenship behaviors on creative behaviors in educational institutions. Procedia - Social and Behavioral Sciences, 235, 342-350. doi:10.1016/j.sbspro.2016.11.042

Amabile, T. M. (1983). The social psychology of creativity: A componential conceptualization. Journal of Personality and Social Psychology, 45(2), 357-376. doi:10.1037/0022-3514.45.2.357

Amabile, T. M., Hill, K. G., Hennessey, B. A., \& Tighe, E. M. (1994). The work preference inventory: Assessing intrinsic and extrinsic motivational orientations. Journal of Personality and Social Psychology, 66(5), 950-967. doi:10.1037/0022-3514.66.5.950

Bagozzi, R. P., Yi, Y., \& Phillips, L. W. (1991). Assessing construct validity in organizational research. Administrative Science Quarterly, 36(3), 421-458. doi:10.2307/2393203

Bies, R. J., \& Moag, J. F. (1986). Interactional justice: Communication criteria of fairness. In R. J. Lewicki, B. H. Sheppard, \& M. H. Bazerman (Eds.), Research on negotiations in organizations (pp. 43-55). London, UK: JAI Press.

Blau, P. M. (1964). Exchange and power in social life. New York, NY: Wiley.

Carbonneau, N., Vallerand, R. J., Fernet, C., \& Guay, F. (2008). The role of passion for teaching in intrapersonal and interpersonal outcomes. Journal of Educational Psychology, 100(4), 977987. doi:10.1037/a0012545

Chan, S. H. J., \& Lai, H. Y. I. (2017). Understanding the link between communication satisfaction, perceived justice and organizational citizenship behavior. Journal of Business Research, 70, 214-223. doi:10.1016/j.jbusres.2016.08.017

Cheasakul, U., \& Varma, P. (2016). The influence of passion and empowerment on organizational citizenship behavior of teachers mediated by organizational commitment. Contaduría y Administración, 61(3), 422-440. doi:10.1016/j.cya.2016.04.003

Cohen, J. (1988). Statistical power analysis for the behavioral sciences. Hillsdale, NJ: Lawrence Erlbaum Associates Publishers.

Cohen-Charash, Y., \& Spector, P. E. (2001). The role of justice in organizations: A metaanalysis. Organizational Behavior and Human Decision Processes, 86(2), 278321. doi:10.1006/obhd.2001.2958

Colquitt, J. A., Conlon, D. E., Wesson, M. J., Porter, C. O. L. H., \& Ng, K. Y. (2001). Justice at the millennium: A meta-analytic review of 25 years of organizational justice research. Journal of Applied Psychology, 86(3), 425-445. doi:10.1037/0021-9010.86.3.425

Colquitt, J. A., Greenberg, J., \& Zapata-Phelan, C. P. (2005). What is organizational justice? A historical overview. In Handbook of organizational justice (pp. 3-56). Mahwah, NJ: Lawrence Erlbaum Associates Publishers. 
Cropanzano, R., \& Mitchell, M. S. (2005). Social exchange theory: An interdisciplinary review. Journal of Management, 31(6), 874-900. doi:10.1177/0149206305279602

De Bernardi, C., \& Pedrini, M. (2020). Entrepreneurial behaviour: Getting eco-drunk by feeling environmental passion. Journal of Cleaner Production, 256, Article 120367. doi:10.1016/j.jclepro.2020.120367

DiPaola, M. F., \& da Neves, P. M. M. C. (2009). Organizational citizenship behaviors in American and Portuguese public schools: Measuring the construct across cultures. Journal of Educational Administration, 47(4), 490-507. doi:10.1108/09578230910967464

Emerson, R. M. (1962). Power-dependence relations. American Sociological Review, 27(1), 31-41. doi: $10.2307 / 2089716$

Fassina, N. E., Jones, D. A., \& Uggerslev, K. L. (2007). Relationship clean-up time: Using metaanalysis and path analysis to clarify relationships among job satisfaction, perceived fairness, and citizenship behaviors. Journal of Management, 34(2), 161-188. doi:10.1177/0149206307309260

Garg, P., \& Rastogi, R. (2006). Climate profile and OCBs of teachers in public and private schools of India. International Journal of Educational Management, 20(7), 529-541. doi:10.1108/09513540610704636

Geisser, S. (1974). A predictive approach to the random effect model. Biometrika, 61(1), 101-107. doi: $10.2307 / 2334290$

Gong, Y., Huang, J.-C., \& Farh, J.-L. (2009). Employee learning orientation, transformational leadership, and employee creativity: The mediating role of employee creative self-efficacy. Academy of Management Journal, 52(4), 765-778. doi:10.5465/AMJ.2009.43670890

Greenberg, J. (1990). Organizational justice: Yesterday, today, and tomorrow. Journal of Management, 16(2), 399-432. doi:10.1177/014920639001600208

Gumusluoglu, L., \& Ilsev, A. (2009). Transformational leadership and organizational innovation: The roles of internal and external support for innovation. Journal of Product Innovation Management, 26(3), 264-277. doi:10.1111/j.1540-5885.2009.00657.x

Hair, J. F., Hult, G. T. M., Ringle, C. M., \& Sarstedt, M. (2017). A primer on Partial Least Squares Structural Equation Modeling (PLS-SEM) (2nd ed.). Thousand Oaks, CA: SAGE Publications.

Hair, J. F., Ringle, C. M., \& Sarstedt, M. (2011). PLS-SEM: Indeed a silver bullet. Journal of Marketing Theory and Practice, 19(2), 139-152. doi:10.2753/MTP1069-6679190202

Henseler, J, Ringle, C. M., \& Sarstedt, M. (2014). A new criterion for assessing discriminant validity in variance-based structural equation modeling. Journal of the Academy of Marketing Science, 43(1), 115-135. doi:10.1007/s11747-014-0403-8

Henseler, J., Ringle, C., \& Sinkovics, R. (2009). The use of partial least squares path modeling in international marketing. Advances in International Marketing, 20, 277-319. doi:10.1108/S1474-7979(2009)0000020014

Homans, G. C. (1958). Social behavior as exchange. American Journal of Sociology, 63(6), 597606. doi: $10.1086 / 222355$

MacKenzie, S. B., Podsakoff, P. M., \& Fetter, R. (1991). Organizational citizenship behavior and objective productivity as determinants of managerial evaluations of salespersons' 
performance. Organizational Behavior and Human Decision Processes, 50(1), 123-150. doi:10.1016/0749-5978(91)90037-T

McFarlin, D. B., \& Sweeney, P. D. (1992). Distributive and procedural justice as predictors of satisfaction with personal and organizational outcomes. Academy of Management Journal, 35(3), 626-637. doi:10.2307/256489

Moorman, R. H. (1991). Relationship between organizational justice and organizational citizenship behaviors: Do fairness perceptions influence employee citizenship? Journal of Applied Psychology, 76(6), 845-855. doi:10.1037/0021-9010.76.6.845

Muthusamy, S. K., \& White, M. A. (2005). Learning and knowledge transfer in strategic alliances: A social exchange view. Organization Studies, 26(3), 415-441. doi:10.1177/0170840605050874

Newman, A., Tse, H. H. M., Schwarz, G., \& Nielsen, I. (2018). The effects of employees' creative self-efficacy on innovative behavior: The role of entrepreneurial leadership. Journal of Business Research, 89, 1-9. doi:10.1016/j.jbusres.2018.04.001

Organ, D. W. (1988). Organizational citizenship behavior: The good soldier syndrome. In Organizational citizenship behavior: The good soldier syndrome. Lexington, Kentucky: Lexington Books/D. C. Heath and Com.

Organ, D. W., Podsakoff, P. M., \& MacKenzie, S. B. (2006). Organizational citizenship behavior: Its nature, antecedents, and consequences. Thousand Oaks, CA: SAGE Publications.

Özdemir, Y., \& Ergun, S. (2015). The relationship between organizational socialization and organizational citizenship behavior: The mediating role of person-environment fit. Procedia Social and Behavioral Sciences, 207, 432-443. doi:10.1016/j.sbspro.2015.10.113

Perry-Smith, J. E. (2006). Social yet creative: The role of social relationships in facilitating individual creativity. Academy of Management Journal, 49(1), 85-101. doi:10.5465/AMJ.2006.20785503

Podsakoff, N. P., Whiting, S. W., Podsakoff, P. M., \& Blume, B. D. (2009). Individual - and organizational-level consequences of organizational citizenship behaviors: A meta-analysis. Journal of Applied Psychology, 94(1), 122-141. doi:10.1037/a0013079

Podsakoff, P. M., \& MacKenzie, S. B. (1994). An examination of the psychometric properties and nomological validity of some revised and reduced substitutes for leadership scales. Journal of Applied Psychology, 79(5), 702-713. doi:10.1037/0021-9010.79.5.702

Podsakoff, P. M., MacKenzie, S. B., \& Fetter, R. (1993). Substitutes for leadership and the management of professionals. The Leadership Quarterly, 4(1), 1-44. doi:10.1016/10489843(93)90002-B

Pritchard, R. D. (1969). Equity theory: A review and critique. Organizational Behavior \& Human Performance, 4(2), 176-211. doi:10.1016/0030-5073(69)90005-1

Rice, G. (2006). Individual values, organizational context, and self-perceptions of employee creativity: Evidence from Egyptian organizations. Journal of Business Research, 59(2), 233241. doi:10.1016/j.jbusres.2005.08.001

Seligman, M. E. P., \& Csikszentmihalyi, M. (2000). Positive psychology: An introduction. American Psychologist, 55(1), 5-14 . doi:10.1037/0003-066X.55.1.5 
Smith, C. A., Organ, D. W., \& Near, J. P. (1983). Organizational citizenship behavior: Its nature and antecedents. Journal of Applied Psychology, 68(4), 653-663. doi:10.1037/0021-9010.68.4.653

Stone, M. (1974). Cross-validatory choice and assessment of statistical predictions. Journal of the Royal Statistical Society. Series B (Methodological), 36(2), 111-147.

Teng, H.-Y. (2019). Job crafting and customer service behaviors in the hospitality industry: Mediating effect of job passion. International Journal of Hospitality Management, 81, 34-42. doi:10.1016/j.ijhm.2019.03.013

Thibaut, J., \& Walker, L. (1975). Procedural justice: A psychological analysis. New York, NY: Lawrence Erlbaum Associates, Hillsdale.

Tran, M. D., \& Nguyen, P. N. (2020). The impact of passion on sales performance: Is negotiation a missing link? Australasian Marketing Journal (AMJ), 28(3), 124-133. doi:10.1016/j.ausmj.2020.05.002

Usmani, S., \& Jamal, S. (2013). Impact of distributive justice, procedural justice, interactional justice, temporal justice, spatial justice on job satisfaction of banking employees. Review of Integrative Business and Economics Research, 2(1), 351-368.

Vallerand, R. J. (2010). On passion for life activities: The dualistic model of passion. Advances in Experimental Social Psychology, 42, 99-100. doi:10.1016/S0065-2601(10)42003-1

Vallerand, R. J., \& Houlfort, N. (2003). Passion at work: Toward a new conceptualization. In S. W. Gilliland, D. D. Steiner, \& D. P. Skarlicki (Eds.), Emerging perspective on values in organizations (pp. 175-204). Charlotte, NC: Information Age Publishing.

Vallerand, R., Blanchard, C., Mageau, G., Koestner, R., Ratelle, C., Léonard, M., ... Marsolais, J. (2003). Les passions de l'ame: On obsessive and harmonious passion. Journal of Personality and Social Psychology, 85, 756-767. doi:10.1037/0022-3514.85.4.756

Whitelock, D., Faulkner, D., \& Miell, D. (2008). Promoting creativity in PhD supervision: Tensions and dilemmas. Thinking Skills and Creativity, 3(2), 143-153. doi:10.1016/j.tsc.2008.04.001

Wong, Y. -T., Ngo, H. -Y., \& Wong, C. -S. (2006). Perceived organizational justice, trust, and OCB: A study of Chinese workers in joint ventures and state-owned enterprises. Journal of World Business, 41(4), 344-355. doi:10.1016/j.jwb.2006.08.003

Zhou, J., \& Hoever, I. (2014). Research on workplace creativity: A review and redirection. Annual Review of Organizational Psychology and Organizational Behavior, 1, 333-359. doi:10.1146/annurev-orgpsych-031413-091226 